\title{
On Markovian Aspect of Academic Staff Structure in Private Higher Institutions
}

\author{
Magbagbeola, Joshua Adekunle O. \\ Joseph Ayo Babalola University,Ikeji-arakeji, Osun State \\ Department of Actuarial Science and Insurance
}

\begin{abstract}
Frustrations, agony and tales of woes that greeted the aftermath of any concluded accreditation exercise informed our interest in addressing this ugly trend that has bedeviled our higher educational system. The dearth or otherwise absence of an appropriate model(s) that will satisfy both the starting matrix and the NUCs staff mix by rank matrix explains this disconnect. A typical challenge here is to reach a desired structure by a certain time in a changing environment or with the smallest possible cost in other to meet up with NUC accreditation minimum bench mark requirement for any higher educational institution. The main objective was to reach a desired structure by a certain time in a changing environment or with the smallest possible cost. Therefore a certain degree of control is sensible at various points in time to the attainment of the desired academic staff structure of any higher institution to monitor the academic staffmix by rank of Academic staff structure of universities not to fall short of NUC requirements for accreditation. In our work, the concept of time as an optimality performance criterion was used to obtain an optimal recruitment control vector for a manpower system modelled by a stochastic differential equation through the necessary condition of Pontryagin theorem. Desired transition matrix P was obtained that is not stochastic but could be further developed into a stochastic matrix as required.
\end{abstract}

\section{Keywords: Markoian, Academic, Staff-mix, Transition Matrix, Accreditation}

\section{Introduction}

Quality is the ability or degree with a product or service or phenomenon conforms, to an established standard, and which makes it to be relatively superior to others. With respect to education this implies the ability or degree with which an educational system (fadipe, 1999). Quality in education therefore means the relevance and appropriateness of the education programme to the needs of the community for which it is provided. Quality assurance on the other hand, is about consistently meeting product specification or getting things right the first time and every time. Quality assurance in the university system implies the ability of the outputs (Ajayi and Akindure, 2007). Equally, it can be said to be the ability of the universities to meet certain criteria relating to academic matters, staff-student ratios, staff mix by rank, staff development, physical facilities, funding and adequate library facilities. Adequately of various inputs via the university system in terms of quarterly and quality, exercise tremendous influence on quality assurance in the university system. Quality assurance is a key component of successful internationalization in the competitive local and global arena and necessary foundation for consumer protection (NUC, 2004)

The control models on the other hand have two aspects: maintainability (maintaining a given structure) and attainability (feasibility of attaining a desired structure): for example Nwaigwe (2008). The demand and supply models are transition models and are concerned with the dynamics of the manpower system and the changing trend of stocks and flows. The dynamics of the system have some undesirable consequences on the structure of the system. For instance, in a graded system, an apparently sensible transition rate may, in due 
course, show a tendency for certain grades to grow at the expenses of others, a transition rate prevailing during a period of economic boom will be too high to maintain during recession, Uche (1984). Therefore, for adequate planning purposes, it is required that the net effect of transitions is zero; a situation we can use the term stationary to describe. This idea plays an important role in manpower planning where objectives can often be stated in terms of achieving a stationary state in which the principal variables have stable and acceptable values. These variables are recruitment, transfers promotions, and retirements. Establishing a stable state as a desirable goal in manpower planning delves naturally into the area of manpower control.

It is evident that 'forces' acting on a manpower system can be divided into two main groups. These are those forces which can be controlled at will by a manpower planner, for example, promotion and recruitment and those which cannot be controlled fully, for example wastage. By judiciously and continually adjusting the controlled variables, we can often get the system to perform in a way consistent with a specific objective. A typical objective may be to reach a desired structure by a certain time in a changing environment or with the smallest possible cost.

The quality of an academic programme becomes a universal concern because the product of one university invariably becomes an employee in another university or other cultures' industrial setting. Also, degree obtained at the end of training in a university is intended to ascertain the level of competency (Ijeoma and Osagie, 2005). The National Universities Commission (NUC, 2006) defined quality assurance as the systematic review of educational programmes to ensure that acceptable standards of, education, scholarship and infrastructure are being maintained. As part of the efforts to ensure qualitative university education in Nigeria, the NUC is particular about ensuring accreditation of academic programmes in Nigerian universities in order to produce graduates who are relevant to the Nigerian economy. Emphasis is laid on the quality of academic staff and students to be admitted and employed respectively.

As opined by (Obadara and Alaka, 2013) a tertiary institution is only as good as the quality of its teaching staff- they are the heart of the institution that produces its graduates, its research products, and its service to the institution, community and nation. According to Hayward (2006) since no nation can develop beyond the quality of its higher education, its therefore of necessary that adequate measure be put in place to guarantee /check the quality delivery. In Nigeria, some of these recent development are reflected in mission statement of the National University Commission (NUC), which is the regulatory body established to oversee the administration and delivery of higher education in Nigeria: to ensure the orderly development of a well-coordinated and productive university system that will guarantee quality and relevant education for national development and global competitiveness (NUC,2009). The council for Higher Education Accreditation (CHEA) in Washington, US defines accreditation as a process of external review used by higher education to scrutinize colleges, universities and educational programme for quality assurance and quality improvement.

The National University Commission (NUC,2006) defined quality assurance as the system review of educational programme to ensure that acceptable standards of education, scholarship and infrastructure are being maintained. As part of the efforts to ensure qualitative university education in Nigeria, the NUC was particular about ensuring accreditation of academic programmes in Nigeria Universities in order to produce graduates who are relevant to the Nigeria economy. Emphasis was laid on the quality of academic staff and students to be admitted and employed respectively. The commission is committed to improving the quality of University programmes through injection of prerequisite inputs as well as assuring quality process and outputs based on the decree 491988 of its scope. The National University Commission is charged to embark on accreditation of quality assurance in Nigeria Universities

\section{Materials and Method}




\subsection{Time Optimality}

\subsubsection{Minimum time Optimality Performance criterion}

Here the control strategy is to be chosen in such a way as to transfer the system from an initial state $\mathrm{n}$ to a desired state $\mathrm{n}^{*}$ in the shortest possible time. This is equivalent to minimizing the performance index,

$$
C=\int_{t_{0}}^{t_{1}} d t
$$

where $t_{1}$ is the first instant of time at which the desired state $n^{*}$ is reached.

\section{Pontryagin Maximum Principle Theorem}

Let $u^{*}(t)$ be an admissible control with corresponding trajectory $\mathrm{n}^{*}$ that transfers a controlled system from $\mathrm{n}_{0}$ at time $\mathrm{t}_{0}$ to $\mathrm{n}_{1}$ at some unspecified time $\mathrm{t}_{1}$. Then in order that $\mathrm{u}^{*}$ and $\mathrm{n}^{*}$ be optimal (that is minimize some performance index) it is necessary that there exist a non-trivial vector $\lambda=\left(\lambda_{0}, \lambda_{1}, \lambda_{2}\right)$ satisfying the Hamiltonian $\mathrm{H}$ and co-state equations such that for every $\mathrm{t}$ in $t_{0} \leq t \leq t_{1}, \mathrm{H}$ attains its maximum with respect to, $\mathrm{u}$ at $u=u^{*}(t)$

$$
H\left(\lambda^{*}, x^{*}, u^{*}\right)=0 \text { and } \lambda_{0} \leq 0 \text { at } \mathrm{t}=\mathrm{t}_{1}
$$

where $\lambda^{*}$ is the solution of the co-state equation for $u=u^{*}(t)$.

Furthermore, it can be shown that $H\left(\phi^{*}(t), x^{*}(t), u^{*}[t]\right)$ and $\lambda_{0}(t)$ are constants so that the Hamiltonian $\mathrm{H}=0$ and $\lambda_{0} \leq 0$ at each point on an optimal trajectory.

The subject of optimal control has attracted the attention of several authors in the mathematical sciences, for example, Washburn (1979), presented a semi-group formulation of boundary input problems for systems governed by parabolic partial differential equation. He established under general condition, a useful bound on the operator kernel of an input map and used the bound to study the input map in a time optimal boundary control problem. Aubin and Clarke (1979), considered a class of optimal control problems in which the cost functional is locally Lipschitz (not necessarily convex or differentiable) and the dynamics linear and/or convex. By using generalized gradient and duality methods of functional analysis, they obtained necessary conditions in which the dual variables admit interpretation as shadow price or rate of change of the value function. In the area of manpower control, a couple of authors have discussed the problem of manpower control in different ways. Mehlmann (1980) for example used the concept of dynamic programming to obtain optimal recruitment and transition strategies within a discrete time Markovian framework. The problem of manpower control by departmentalization in an extended Markov framework is extensively discussed in Ossai (2008). Udom and Uche (2008) developed an optimal promotion cost control model for distinguishing different promotion control strategies. This optimal cost model is able to tackle the problem which arose in Uche (1984) in which the solution to a control equation resulted to a set of admissible promotion control strategies.

In most manpower control problems, there may be more than one way of reaching a desired structure or maintaining a given structure. In situations like this, one is faced with the problem of selecting the control strategy that is best in some sense. This is an aspect of optimal manpower control in which, interest is on the problem of compelling a system in this case, a manpower system to behave in some best possible way. Definitely, the exact control strategy depends on the criterion used to decide what is meant by best. This work will examine the condition under which a manpower system modeled by a differential equation is 
controllable and uses time as an optimality performance criterion in controlling the manpower system with quadratic index in both state and control spaces.

\subsection{1a Markov and Renewal Manpower Models}

Ogbogbo, Ebuh and Aronu (2013) opined in their work that Markov models start with a given group of employees that exist in a level of the organization; given the flows in and out of each level (i.e. recruitment and promotions from outside the system together with wastage) they estimate the population of the level in the future. This type of model is particularly useful when the knowledge of existing employees are available together with the probabilities of flows between succeeding years and the required future manpower is not known. Markov models are based on the assumption that future employees in any level of the organization are determined not so much by the number required in that level of the organization but by the promotions and recruitment encouraging the movement up through the system. Because of this characteristic of "pushing" Markov models are often called "push" models. Renewal models concentrate on the basic assumption that requirements are met by changes in promotions and recruitment rates. Knowing the manpower requirements, what is required therefore is knowledge of how much recruitment and how many promotions should take place to satisfy them. In this way employees are "pulled" through the system to meet predetermined requirements of the system. Equally, because of this, renewal models are often called "pull" models. Applying the manpower method in an Organisation with grades, a staff member can join the grades with equal probability and the entry into the system at the grade is independent of what happens at lower grades within the system, a staff member can be promoted to the next higher grade, stay in the present grade or leave the system by dismissal, retirement, death or for whatever reason each year.

\subsubsection{Estimating a Markov Transition Matrix from Observed Data}

Markov chains play a central role in Operational Research, frequently being used to describe how a system changes over time. If a system can be adequately modelled as a Markov chain, then numerous theoretical consequences can be applied to the analysis of the system. The behavior of a Markov Chain depends on the values used in the transition matrix which specifies probabilities that the system moves from one state to another in unit time. Standard texts assume that the values of such transition matrices are known. However, in most practical studies, this is not the case and the transition matrix needs to be estimated. One way of doing such estimation is to use data concerning the observed state of the system at successive time 'point'. If succeed, observations are all the same interval apart then estimating the transition matrix is straightforward. Unfortunately, however, the practitioner is often faced with problems in which, a system has been observed infrequently, where times between successive observations vary. With a large amount of such variation, estimating the transition matrix becomes more complex. Horn (1975), Chung (1967), Crane and Iglehart (1974a, 1974b and 1975) and Iglehart (1975) opined in their works the essence of Markov chain and its transition matrix.

\subsubsection{Markov Chain Analysis of Manpower Data of A Nigerian University}

According to Igboanugo and Onifade (2011), the approach to manpower policy especially in most Nigerian universities appears to be guided by the traditional method of putting the right number of people in the right place at the right time or arranging for suitable number of people to be allocated to various jobs usually in a hierarchical structure. The technique is outdated because it lags behind the state-of-the-art method that deals with manpower policy in the context of organizational strategy. The traditional method is deficit in the sense that it neither in the offers computational tools that will enable managers to determine possible line of action to be taken to steer manpower policy to desired ends nor provide tools to generate alternative policies and strategies. Government is concerned about these policies to the extent that the National Universities Commission (NUC) embarks on regular staff audit which focuses on fishing out ghost workers, (rightsizing) to reduce overhead and aligning employment policy to strategic goals. The method advocated is exploratory and through its computational tools, can generate outcomes that will enable normative models to be 
formulated. In this regard, prescriptive standard that can guide manpower policy to the desired direction can be easily established. The traditional methods are naïve and therefore lack this potency. Especially in this time of developmental update coupled with the need to be highly scientific in our approach to problem solving. The need for development of a Transition matrix that will assist educational practitioners and administrators in solving manpower planning problem occasioned by inadequacies noted during NUC accreditation exercise in our universities in Nigerian at this time cannot be overemphasized. Going by the growing need for more universities to be establish in the wake of admission challenge (inability to adequately admit all willing candidates); and incessant strikes in the public universities. A perfect blend of quality marched with quantity which is occasioned by the constant enrolment of candidates into the institution on annual basis is germane.

\section{Results and Discussion}

Objective: To have a Transition matrix $\mathrm{P}$ that enables a department to be able to readjust the staff-mix, so as to meet NUC staff-mix requirement.

Observably, seven states are required as follows:

1. Recruitment pool for Lecturer $1 \&$ below as state $1\left(L 1 \leq^{\prime}\right)$

2. Recruitment pool for Senior Lecturer as state $2\left(S L^{\prime}\right)$

3. Recruitment pool for Professorial cadre as state $3\left(\operatorname{Pr}^{\prime}\right)$

4. Lecturer $1 \&$ below $\rightarrow$ Lecturer $1 \&$ below $\rightarrow$ Senior Lecturer $\rightarrow$ Professor $\rightarrow$ Exit as state $4(L 1 \leq$ )

5. Senior Lecturer $\rightarrow$ Senior Lecturer $\rightarrow$ Professor $\rightarrow$ Exit as state $5(S L)$

6. Professor $\rightarrow$ Professor $\rightarrow$ Exit as state 6 ( Pr)

7. Exit from the department as state 7 (E)

Let $\mathrm{P}$ be the required Transition Probability Matrix given as:

$P=\left[\begin{array}{lllllll}a_{11} & a_{12} & a_{13} & a_{14} & a_{15} & a_{16} & a_{17} \\ a_{21} & a_{22} & a_{23} & a_{24} & a_{25} & a_{26} & a_{27} \\ a_{31} & a_{32} & a_{33} & a_{34} & a_{35} & a_{36} & a_{37} \\ a_{41} & a_{42} & a_{43} & a_{44} & a_{45} & a_{46} & a_{47} \\ a_{51} & a_{52} & a_{53} & a_{54} & a_{55} & a_{56} & a_{57} \\ a_{61} & a_{62} & a_{63} & a_{64} & a_{65} & a_{66} & a_{67} \\ a_{71} & a_{72} & a_{73} & a_{74} & a_{75} & a_{76} & a_{77}\end{array}\right]$

Where ${ }^{a_{i j}}$ is the probability of movement from state i to j. e.g. ${ }^{a_{15}}$ is the probability of being recruited from the pool of $L 1 \leq^{\prime}$ to the position of SL and ${ }^{a_{57}}$ is the probability of exiting from the department. For each i,

If $X^{N}$ is the NUC staff mix and $X^{S}$ is the present staff-mix available in the department, for a case of denial accreditation status that requires one year for the department to readjust

$X^{F}=P^{1} X^{S}$

For cases that requiresn years to ensure NUC staff-mix where $\mathrm{n}$ stands for interim and full accreditation. e.g 2,3 , and 4years

$X^{F}=P^{n} X^{S}$ 
In $\mathrm{P}$ above, some transitions are impossible e.g. A professor moving to the state of $L 1 \leq$

Starting from state $1, L 1 \leq^{\prime}$ the recruitment can only be to $\mathrm{L} 1<$ or remain in state 1 unrecruited.

$\begin{array}{lllllll}1 & 2 & 3 & 4 & 5 & 6 & 7\end{array}$

$\begin{array}{llllllll}\text { State } 1 & a_{11} & 0 & 0 & a_{14} & 0 & 0 & 0\end{array}$

Staring from state $2, S L^{\prime}$ recruitment pool to SL

$\begin{array}{lllllll}1 & 2 & 3 & 4 & 5 & 6 & 7\end{array}$

$\begin{array}{llllllll}\text { State } 2 & 0 & a_{22} & 0 & 0 & a_{25} & 0 & 0\end{array}$

Similarly for state $3, \mathrm{Pr}^{\prime}$ recruitment pool for $\mathrm{Pr}$

$\begin{array}{lllllll}1 & 2 & 3 & 4 & 5 & 6 & 7\end{array}$

$\begin{array}{llllllll}\text { State } 3 & 0 & 0 & a_{33} & 0 & 0 & a_{36} & 0\end{array}$

State 4- present staffing of L1<. Transition can only be to state 5 i.e. SL and Pr. State 5 and 6 and exit $\begin{array}{lllllll}1 & 2 & 3 & 4 & 5 & 6 & 7\end{array}$

$\begin{array}{llllllll}\text { State } 4 & 0 & 0 & 0 & a_{44} & a_{45} & a_{46} & a_{47}\end{array}$

Similarly, for state 5 - present staffing of SL, where transition is to Pr or exit

$$
\begin{array}{lllllll}
1 & 2 & 3 & 4 & 5 & 6 & 7
\end{array}
$$

$\begin{array}{llllllll}\text { State } 5 & 0 & 0 & 0 & 0 & a_{55} & a_{56} & a_{57}\end{array}$

For Pr state transition is to exit

$\begin{array}{lllllll}1 & 2 & 3 & 4 & 5 & 6 & 7\end{array}$

$\begin{array}{llllllll}\text { State } 6 & 0 & 0 & 0 & 0 & 0 & a_{66} & a_{67}\end{array}$

State 7- The Exit state, here no transition

$\begin{array}{llllllll}\text { State } 7 & 0 & 0 & 0 & 0 & 0 & 0 & 1\end{array}$

Putting all these together,

$a_{i j}=\left[\begin{array}{ccccccc}a_{11} & 0 & 0 & a_{14} & 0 & 0 & 0 \\ 0 & a_{22} & 0 & 0 & a_{25} & 0 & 0 \\ 0 & 0 & a_{33} & 0 & 0 & a_{36} & 0 \\ 0 & 0 & 0 & a_{44} & a_{45} & a_{46} & a_{47} \\ 0 & 0 & 0 & 0 & a_{55} & a_{56} & a_{57} \\ 0 & 0 & 0 & 0 & 0 & a_{66} & a_{67} \\ 0 & 0 & 0 & 0 & 0 & 0 & 1\end{array}\right]$ 
$\sum_{j=1}^{7} a_{i j}=1$ for all i

\section{Interim - One Year Transition}

$X^{F}=P^{1} X^{S}$

$\left[\begin{array}{c}X_{1}^{F} \\ X_{2}^{F} \\ X_{3}^{F} \\ X_{4}^{F} \\ X_{5}^{F} \\ X_{6}^{F} \\ X_{7}^{F}\end{array}\right]=\left[\left(a_{i j}\right)\right]\left[\begin{array}{c}X_{1}^{S} \\ X_{2}^{S} \\ X_{3}^{S} \\ X_{4}^{S} \\ X_{5}^{S} \\ X_{6}^{S} \\ X_{7}^{S}\end{array}\right]$

Equation becomes,

$a_{11} X_{1}^{S}+a_{14} X_{4}^{S}=X_{1}^{F}$

$a_{22} X_{2}^{S}+a_{25} X_{5}^{S}=X_{2}^{F}$

$a_{33} X_{3}^{S}+a_{36} X_{6}^{S}=X_{3}^{F}$

$a_{44} X_{4}^{S}+a_{45} X_{5}^{S}+a_{46} X_{6}^{S}+a_{47} X_{7}^{S}=X_{4}^{F}$

$a_{55} X_{5}^{S}+a_{56} X_{6}^{S}+a_{57} X_{7}^{S}=X_{5}^{F}$

$a_{66} X_{6}^{S}+a_{67} X_{7}^{S}=X_{6}^{F}$

$a_{67} X_{7}^{S}=X_{7}^{F}$

Giving rise to 16 unknowns in seven equations. The following additional equations are deduced as follows (available stock of staff in the department):

Total number of L1<

$a_{14}+a_{44}$

Representing the sum of those recruited and not promoted

Total number of SL

$a_{25}+a_{45}+a_{55}$

Typifies, sum of recruited, promoted and not promoted

Total number of Pr

$a_{36}+a_{46}+a_{56}+a_{66}$ 
Equation (8) is as $X_{4}^{S}$

Equation (9) is as $X_{5}^{S}$

Equation (10) is as $X_{6}^{S}$

$\Rightarrow a_{14}+a_{44}=X_{4}^{F}$

$a_{25}+a_{45}+a_{55}=X_{5}^{F}$

$a_{36}+a_{46}+a_{56}+a_{66}=X_{6}^{F}$

Additional equations are (taking the row sum)

$a_{11}+a_{14}=1$

$a_{22}+a_{25}=1$

$a_{33}+a_{36}=1$

$a_{44}+a_{45}+a_{46}+a_{47}=1$

$a_{55}+a_{56}+a_{57}=1$

$a_{66}+a_{67}=1$

Giving rise to 16 equations and 16 unknowns

From equation (10), $a_{67}=\left(1-a_{66}\right)$

Applied to equation (6)

$\left(1-a_{66}\right) X_{7}^{S}+a_{66} X_{6}^{S}=X_{6}^{F}$

$X^{S}=\left[\begin{array}{lllllll}0 & 0 & 0 & X_{4}^{S} & X_{5}^{S} & X_{6}^{S} & X_{E}^{S}\end{array}\right]$, since $X_{7}^{S}=0$

Hence, $a_{66}=\frac{X_{6}^{F}}{X_{5}^{S}}$

From equation (15), $a_{57}=\left(1-a_{55}-a_{56}\right)$

Substituting into equation (5)

$a_{55} X_{5}^{S}+a_{56} X_{6}^{S}+a_{57} X_{7}^{S}=X_{5}^{F}$

If $X_{7}^{S}=0$

$a_{55} X_{5}^{S}+a_{56} X_{6}^{S}=X_{5}^{F}$ 


\section{Assumption 1}

From available data, promotion exercise for the last four years; the probability of promotion from SL to Pr given as ${ }^{a_{56}}$ which giving a prior probability relationship between $a_{55}$ and $a_{56}$.

For example, for every 9 that remains in SL one is promoted to Pr giving a ratio of ${ }^{a_{55}}:{ }^{a_{56}}$ as $9: 1$.

Then equation (18) becomes

$$
\begin{aligned}
& a_{55} X_{5}^{S}+\frac{a_{55}}{9} X_{6}^{S}=X_{5}^{F} \\
& a_{55}\left(X_{5}^{S}+\frac{1}{9} X_{6}^{S}\right)=X_{5}^{F} \\
& a_{55}=\frac{X_{5}^{F}}{\left(X_{5}^{s}+\frac{1}{9} X_{6}^{S}\right)}, \text { then } a_{56} \text { and } a_{57}
\end{aligned}
$$

From equation (14)

$a_{44}+a_{45}+a_{46}+a_{47}=1$

$a_{47}=1-a_{44}-a_{45}-a_{46}$

Substitute into equation (4)

$$
\begin{aligned}
& a_{44} X_{4}^{S}+a_{45} X_{5}^{S}+a_{46} X_{6}^{S}+\left(1-a_{44}-a_{45}-a_{46}\right) X_{7}^{S}=X_{4}^{F} \\
& a_{44}\left(X_{4}^{S}-X_{7}^{S}\right)+a_{45}\left(X_{5}^{S}-X_{7}^{S}\right)+a_{46}\left(X_{6}^{S}-X_{7}^{S}\right)=X_{4}^{F}-X_{7}^{S}
\end{aligned}
$$

Since $X_{7}^{S}=0$

$a_{44} X_{4}^{S}+a_{45} X_{5}^{S}+a_{46} X_{6}^{S}=X_{4}^{F}$

\section{Assumption 2}

$a_{46}$ is the transition from $\mathrm{L} 1<$ to Pr in the first year which is close to zero

Then equation (20) becomes

$a_{44} X_{4}^{S}+a_{45} X_{5}^{S}=X_{4}^{F}$

If $a_{44}: a_{45}$ as $8: 2$, then equation (21) becomes

$a_{44} X_{4}^{S}+\frac{2}{10} a_{44} X_{5}^{S}=X_{4}^{F}$

$a_{44}\left(X_{4}^{S}-\frac{1}{5} X_{5}^{S}\right)=X_{4}^{F}$ 
$a_{44}=\frac{X_{4}^{F}}{X_{4}^{S}-\frac{1}{5} X_{5}^{S}}$

Then follows ${ }^{a_{45} \text { and }} a_{46}$

From equation (8) and since $a_{44}$ is known, then

$a_{14}=X_{4}^{F}-a_{44}$

Substituting into equation (11), we get $a_{11}$

From equation (9),

$a_{25}=X_{5}^{F}-a_{45}-a_{55}$,

$a_{45}$ and $a_{55}$ are already known

From equation (12)

$a_{22}=1-a_{25}$

In equation (10) substitute for $a_{66},{ }^{a_{56}}$ and ${ }^{a_{46}}$ then we have ${ }^{a_{36}}$

Then from equation (13) we obtain

$a_{33}=1-a_{36}$

Additional Equations (Based on Current + Recruited=Final Stock)

$$
\begin{aligned}
& a_{55}+a_{56}+a_{57}=X_{5}^{S} \\
& a_{66}+a_{67}=X_{6}^{S} \\
& a_{44}+a_{45}+a_{46}+a_{47}=X_{4}^{S} \\
& a_{36}+a_{46}+a_{56}+a_{66}=X_{6}^{F} \\
& a_{25}+a_{41}+a_{55}=X_{4}^{F} \\
& a_{14}+a_{44}=X_{4}^{F} \\
& a_{11}+a_{14}=X_{1}^{S} \\
& a_{22}+a_{23}=X_{2}^{S} \\
& a_{33}+a_{36}=X_{3}^{S}
\end{aligned}
$$


$P=\left[\begin{array}{ccccccc}a_{11} & 0 & 0 & a_{14} & 0 & 0 & 0 \\ 0 & a_{22} & 0 & 0 & a_{25} & 0 & 0 \\ 0 & 0 & a_{33} & 0 & 0 & a_{36} & 0 \\ 0 & 0 & 0 & a_{44} & a_{45} & a_{46} & a_{47} \\ 0 & 0 & 0 & 0 & a_{55} & a_{56} & a_{57} \\ 0 & 0 & 0 & 0 & 0 & a_{66} & a_{67} \\ 0 & 0 & 0 & 0 & 0 & 0 & 1\end{array}\right]$,

$X^{S}=\left[\begin{array}{c}X_{1}^{S} \\ X_{2}^{S} \\ X_{3}^{S} \\ X_{4}^{S} \\ X_{5}^{S} \\ X_{6}^{S} \\ X_{7}^{S}\end{array}\right]=\left[\begin{array}{c}0.01 \\ 0.02 \\ 0.03 \\ 5 / 8 \\ 2 / 8 \\ 1 / 8 \\ 0\end{array}\right], X^{F}=\left[\begin{array}{c}X_{1}^{F} \\ X_{2}^{F} \\ X_{3}^{F} \\ X_{4}^{F} \\ X_{5}^{F} \\ X_{6}^{F} \\ X_{7}^{F}\end{array}\right]=\left[\begin{array}{c}0 \\ 0 \\ 0 \\ 0.45 \\ 0.35 \\ 0.20 \\ 0\end{array}\right]$

Note: $X_{1}^{S}=0.01, X_{2}^{S}=0.02, X_{3}^{S}=0.03$ are all assigned values as $X_{1}^{S}, X_{2}^{S}, X_{3}^{S} \prec 0$. This explains the fact that the recruitment pool can never be empty due to prevalent unemployment.

$a_{11}=1-a_{14}$

$a_{14}=X_{4}^{F}-\left(\frac{X_{4}^{F}}{X_{4}^{S}-\frac{1}{5} X_{5}^{S}}\right)$

$a_{22}=1-a_{25}$

$a_{25}=X_{5}^{F}-a_{45}-a_{55}$

$a_{33}=1-a_{36}$

$a_{36}=X_{6}^{F}-a_{46}-a_{56}-a_{66}$

$a_{44}=\frac{X_{4}^{F}}{X_{4}^{S}-\frac{1}{5} X_{5}^{S}}$

$a_{45}=\frac{X_{4}^{F}-\left(\frac{X_{4}^{F}}{X_{4}^{S}-\frac{1}{5} X_{5}^{S}}\right) X_{4}^{S}}{X_{5}^{S}}$

$a_{46}=\frac{X_{4}^{F}-a_{44} X_{4}^{S}-a_{45} X_{5}^{S}}{X_{6}^{S}}$ 
$a_{47}=1-a_{44}-a_{45}-a_{46}$

$a_{55}=\frac{X_{5}^{F}}{\left(X_{5}^{S}+\frac{1}{9} X_{6}^{S}\right)}$

$a_{56}=\frac{X_{5}^{F}-a_{55} X_{5}^{S}}{X_{6}^{S}}$

$a_{57}=\frac{X_{5}^{F}-a_{55} X_{5}^{S}-a_{56} X_{6}^{S}}{X_{7}^{S}}$

$a_{66}=\frac{X_{6}^{F}}{X_{5}^{S}}$

Note: $X^{S}$ is based on the available staff stock in a particular department but in our case study i.e. $\mathrm{L} 1<=5$, $\mathrm{SL}=2$ and $\operatorname{Pr}=1$.

$P=\left[\begin{array}{ccccccc}1.3326 & 0 & 0 & -0.3326 & 0 & 0 & 0 \\ 0 & 0.1796 & 0 & 0 & -0.8204 & 0 & 0 \\ 0 & 0 & 1.7464 & 0 & 0 & -0.7464 & 0 \\ 0 & 0 & 0 & 0.7826 & -0.1564 & 0 & 0.3738 \\ 0 & 0 & 0 & 0 & 1.3268 & 0.1464 & \infty \\ 0 & 0 & 0 & 0 & 0 & 0.8 & 0.2 \\ 0 & 0 & 0 & 0 & 0 & 0 & 1\end{array}\right]$

The matrix P obtained for this test case is not stochastic as the row sum for Rows 2 and 5 does not sum up to 1. Therefore, there is the need to make it stochastic as the matrix is representative of the solution to required staff-mix needed to meet up NUC requirement. Obtained transition matrix P in its non-stochastic state can still be used to obtain the required staff-mix by rank for the accreditation purpose and later made stochastic. This is left for further study (making the obtained matrix become stochastic).

\section{Conclusion and Recommendations}

A manpower system is modelled as stochastic differential equation. The concept of time as an optimality performance criterion is proposed to be adapted to obtain optimal recruitment control vector for the manpower system through the necessary condition of Pontryagin theorem. It will be shown that the optimal recruitment control vector to minimised the control time globally.

\section{References}

[1] Aubin, J-P., F.H. Clarke. 1979. Shadow prices and duality for a class of optimal control problems, SIAM J. of Control, 17 no.5, pp.567-586.

[2] Alexander Mehlmann (1980), An Approach to Optimal Recruitment and Transition Strategies for Manpower Systems using Dynamic Programming, The Journal of the Operational Research Society, Vol. 31, No. 11 (Nov., 1980), pp. 1009-1015

[3] Ajayi, I.A and Akindutire, I.O (2007), The unresolved issues of quality assurance in Nigeria University, Journal of sociology and Education in Africa,6(1),1-16. 
[4] Fadipe, J.O (1999). Quality control in education. In A.A Olagboye and J.O Fadipe(Eds). Management of Nigerian Education; Law, structures, responsibilities, Ondo: NIEPA.

[5] National University Commission (2004). The sole of National Universities Commission in quality assurance in Nigerian Universities: Nigeria University system news, 12(1),2.

[6] Obadara, O.E and Alaka,A.A (2013) Accreditation and quality Assurance in Nigerian Universities; Journal of Education and practice, Vol. 4, No8, pp34-41.

[7] National University Commission (2009), weekly Bulletin, 4(46), November,9

[8] National University Commission (2006), "Accreditation of Nigeria Universities"

[9] Hayward, F.M.(2008) Accreditations and quality assurance in University education in developing countries. Washington Dc, United State of America.

[10] Hayward, F. M. (2006). Accreditation and quality assurance in university education in developing countries. Washington DC, United State of America.

[11]Horn, H. S. (1975). Markovian properties of forest succession. In: Ecology and evolution of communities (edited by M. L. Cody and J. M. Diamond), pp. 126-211. Cambridge, Mass.: Harvard University Press.

[12] Igboanugo, A.C. and Onifade, M.K.: JOIRES 2(2), April, 2011: 107-123.

[13]Ijeoma, M. E. and Osagie, R. O. (2005). Strategies for quality assurance in higher education. A paper presented at the 29lh Annual National Conference of the National for Educational Administration and Planning (NAEAP) at the University of Calabar, Calabar, Nigeria.

[14] Iglehart. D. L. (1975). Simulating Stable Stochastic Systems, V: Comparison Of Ratio Estimators. Naval Res. Logist. Quart. 22, 553-565.

[15] Nwaigwe, C.C. (2008). On the recruitment and promotion manpower control using markov theory. Journal of Research in Physical Sciences. 4(2):87-91.

[16] National Universities Commission (2004). The role of National Universities Commission in quality assurance in Nigeria universities. Nigeria University System News, 12(1), 2.

[17] National Universities Commission (2006). "Accreditation of Nigeria universities".

[18] National Universities Commission (2009). Weekly Bulletin, 4(46), November, 9.

[19] Obadara, O.E. and Alaka, A.A. (2013).Accreditation and Quality Assurance in Nigerian Universities, Journal of Education and Practice, 4(8), 34-41.

[20] Ogbogbo, G. O., Ebuh, G. U., Aronu, C. O (2013). Prediction of Academic Manpower System of a Polytechnic Institution in Nigeria. Science Journal of Applied Mathematics and Statistics. Vol. 1, No. 5, pp. 54-61.

[21] Ossai, E. O. (2008). Statistical control models in graded and departmentalized manpower systems. Ph.D. thesis, Univ. Nigeria, Nsukka.

[22] Uche, P.I. (1984). Some control measures for markov systems. Int. J. Math. Educ. Sci. Tech. 15(4):479-483.

[23] Udom, A.U and Uche, P.I. (2009). The use of an optimality performance criterion in manpower planning control. The Pacific Journal of Science and Technology, 10(1), pp. 197-203. 